\title{
ESTUDO COMPARATIVO DA PRODUÇÃO LEITEIRA EM MUNICÍPIOS DA REGIÃO SUL DO RIO GRANDE DO SUL
}

\section{RESUMO}

A produção brasileira de leite se caracteriza por conter sistemas individuais de produção. Assim, objetivou-se caracterizar a produção leiteira em municípios da região sul do Rio Grande do Sul e verificar os fatores que mais afetam a qualidade do leite nessa região, através de um inquérito epidemiológico e análises de qualidade do leite nas unidades de produção. A investigação mostrou que a idade média dos produtores é de 49 anos, e $64,15 \%$ destes não concluíram o ensino fundamental. A produção de leite é realizada em propriedades com média de 26,06 hectares, com 8,4 vacas em lactação em média, sendo que $93,6 \%$ das unidades possuem menos de 20 vacas. A maioria das unidades (32,83\%) produz de 50 a $100 \mathrm{~L} /$ dia; $13,21 \%$ produzem até $30 \mathrm{~L} /$ dia e apenas 1,89\% produz acima de $500 \mathrm{~L} /$ dia. A produtividade média detectada foi de 6,8 L/vaca/dia. Quanto ao manejo da ordenha, 39,3\% ainda ordenham seus animais manualmente, apenas $14,2 \%$ desinfetam o teto antes da ordenha e 53,9\% utilizam um único pano para secagem dos tetos. Observou-se correlação negativa entre a contagem de células somáticas (CCS) e a produção leiteira $(r=-0,23)$ e entre CCS e teor de lactose $(r=-0,39)$. Houve correlação positiva entre teor de lactose e produção $(r=0,31)$. Os dados comprovam que o produto obtido tem qualidade inferior em locais onde são adotadas técnicas precárias de manejo.

Palavras-chave: Ordenha. Pequenos produtores. Qualidade do leite. 


\section{INTRODUÇÃO}

A produção de leite no Brasil possui importância socioeconômica significativa. O país é o sexto maior produtor mundial e, apenas no primeiro trimestre de 2015 registrou 6,128 bilhões de litros de leite adquiridos sob algum tipo de fiscalização sanitária (USDA, 2014; IBGE, 2015). Dentre os estados brasileiros, o Rio Grande do Sul é o segundo maior produtor nacional de leite, com $10,6 \%$ da produção brasileira e é o Estado que mais contribui para a produção geral da região sul do Brasil. No primeiro trimestre de 2015, registrou pouco mais de 846 milhões de litros de leite adquirido sob inspeção sanitária (IBGE, 2015). Apesar da relevância da produção leiteira no país, existem fatores que comprometem seu progresso como baixo nível de instrução dos produtores e a falta de assistência técnica, por exemplo, são entraves no avanço da produção de leite com qualidade (SCALCO; SOUZA, 2006).

De maneira geral, os produtores encaram a produção de leite como um complemento da renda, o que afeta a produtividade da atividade, que é baixa (SCHUCH et al., 2009). A redução na produção ocorre, principalmente, devido à mastite e é influenciada pela gravidade da infecção, tipo de micro-organismo causador, duração do processo, idade do animal, época do ano, estado nutricional e potencial genético (SCHULTZ, 1977).

Uma ferramenta utilizada para o monitoramento da qualidade do leite é a Contagem de Células Somáticas (CCS), que engloba principalmente células de defesa presentes no leite em caso de infecção na glândula mamária (COSTA; WATANABE, 1999), mensurando assim os índices de mastite do rebanho ou animal (SCHÄELLIBAUM, 2000). A CBT (Contagem Bacteriana Total) é parâmetro utilizado para a avaliação da qualidade do leite e se relaciona com a higiene no processo de ordenha e estocagem do produto (BRASIL, 2011; BRITO et al., 2002).

Além do aumento da CCS, quadros de mastite levam a alterações dos teores de lactose, proteína e gordura, aumento na passagem de íons cloretos e outras substâncias do sangue para o leite, gerando desequilíbrios que podem causar diminuição no rendimento do leite para subprodutos (TOZZETTI et al., 2008).

Este estudo objetivou caracterizar os sistemas de produção leiteira e verificar os fatores que mais afetam a qualidade do leite no sul do Rio Grande do Sul. 


\section{MATERIAL E MÉTODOS}

Foram visitadas 274 Unidades Produtoras de Leite (UPL) em seis municípios da região sul do Rio Grande do Sul: 65 em Pelotas, 69 em Canguçu, 62 em Cerrito, 16 em Rio Grande, 37 em Morro Redondo e 25 em São Lourenço do Sul, que representam 6,2\%, 2,9\%, 18,3\%, 7,2\%, $10,5 \%$ e $1,7 \%$, respectivamente, do número de UPL que comercializaram leite, conforme o censo agropecuário realizado pelo Instituto Brasileiro de Geografia e Estatística (IBGE, 2006). As visitas tiveram objetivo de obter dados necessários para a caracterização das UPL, e coleta de amostras de leite para análises de qualidade. Um questionário epidemiológico foi aplicado diretamente aos responsáveis pelas UPL, abordando temas relacionados ao proprietário, à propriedade, ao rebanho leiteiro, a produção de leite e ao manejo de ordenha.

Em cada UPL avaliada foram coletadas duas amostras de leite, provenientes do resfriador, com aproximadamente $50 \mathrm{~mL}$, devidamente identificadas. Os recipientes continham pastilhas de conservantes, um com bronopol ${ }^{\circledR}$ (2bromo-2nitropropano-1,3diol) e outro com azidiol (azida sódica e cloranfenicol). Para a coleta em tanques de imersão, o leite foi misturado com um homogeneizador inoxidável de cabo longo, e em tanques de expansão, a homogeneização foi feita ligando o equipamento durante cinco minutos. Antes de cada coleta, para assepsia, o copo coletor inoxidável foi imerso em álcool $70^{\circ} \mathrm{GL}$.

As amostras foram encaminhadas, sob refrigeração, ao Laboratório de Qualidade de Leite da Empresa Brasileira de Pesquisa Agropecuária - EMBRAPA - Clima Temperado, onde a CBT e CCS foram realizadas por citometria de fluxo em equipamento Somacount $300^{\circledR}$. A verificação dos teores de lactose, gordura, proteínas e sólidos totais foi feita através de espectrofotometria por radiação infravermelha em equipamento Bentley $2000^{\circledR}$.

A análise estatística foi realizada através de análise de variância com comparação entre médias pelo teste Tukey. Para análise de freqüências das variáveis tipo de ordenha, desinfecção e secagem dos tetos, tipo de instalações e piso do local de ordenha em que haviam respostas pré-definidas foi utilizado o teste Qui-Quadrado para determinar 
diferenças entre os municípios. Foram obtidos os coeficientes de correlação de Pearson comparando entre si CCS, CBT e os teores de gordura, proteínas, lactose e sólidos totais no leite. O nível de significância adotado em todas as análises foi de $95 \%$. Todas as análises foram realizadas utilizando o software estatístico Statistical Analysis System (SAS, 2004).

\section{RESULTADOS E DISCUSSÃO}

No Brasil, o nível de instrução dos proprietários das UPL determina o grau de conhecimento e comprometimento com a atividade leiteira (MILANI et al., 2012). Segundo este pesquisador, os filhos de produtores que pretendem continuar com a atividade leiteira, no geral, não completam o ensino médio e, aqueles que pretendem concluir os estudos, não almejam continuar com a atividade leiteira, e saem do campo para trabalhar em outra atividade ou cursar o terceiro grau. Em 32\% dos casos apenas os pais permanecem trabalhando na propriedade.

A Tabela 1 apresenta dados referentes à caracterização dos produtores rurais nos municípios estudados. Os municípios de Pelotas, Cerrito, Rio Grande e Morro Redondo atingiram níveis próximos de $70 \%$ dos produtores sem ensino fundamental completo, com $4,89 \%$ se enquadrando na faixa do analfabetismo. A baixa escolaridade prejudica a incorporação de novas tecnologias e o entendimento da importância do correto manejo de ordenha, por exemplo.

Tabela 1 - Caracterização de produtores de leite de municípios da região sul do Rio Grande do Sul, segundo a idade média e o grau de instrução $(n=274)$.

\begin{tabular}{llllllll}
\hline \multirow{2}{*}{ Município (n) } & Idade & \multicolumn{2}{l}{ Grau de instrução (\%) } & & & \\
\cline { 3 - 8 } & média & $\mathbf{1}$ & $\mathbf{2}$ & $\mathbf{3}$ & $\mathbf{4}$ & $\mathbf{5}$ & $\mathbf{6}$ \\
\hline Pelotas (65) & 51 & 2,92 & 74,27 & 15,8 & 1,75 & 3,51 & 1,75 \\
Canguçu (69) & 49 & 0 & 43,48 & 50,72 & 4,35 & 0 & 1,45 \\
Cerrito (62) & 49 & 8,06 & 72,58 & 14,52 & 3,23 & 1,61 & 0 \\
Rio Grande (16) & 43 & 6,25 & 68,7 & 0 & 18,8 & 0 & 6,25 \\
Morro Redondo (37) & 49 & 2,7 & 75,69 & 8,1 & 5,41 & 8,1 & 0 \\
São Lourenço do Sul (25) & 49 & 4 & 60 & 24 & 4 & 8 & 0
\end{tabular}

1 - Analfabetos; 2 - Ensino fundamental incompleto; 3 - ensino fundamental completo; 4 - ensino médio incompleto; 5 - ensino médio completo; 6 - ensino superior. 
Em estudo semelhante, Picoli et al. (2015) estudaram, na microrregião de Pelotas, RS, as características da produção leiteira em função da instrução dos produtores rurais e observaram que a idade média dos produtores era de 49 anos e que 67,9\% destes não concluíram o ensino fundamental, e apenas $3 \%$ concluíram o ensino médio. Os resultados obtidos corroboram com Milani et al. (2012) e indicam a precariedade do ensino no meio rural. As razões podem variar, como a falta de incentivo aos jovens, que muitas vezes preferem continuar com a atividade que a família exerce há gerações, ou até mesmo a falta de políticas públicas que facilitem o ensino em áreas rurais.

Quanto à caracterização das propriedades e da produção de leite, os resultados encontramse alocados na Tabela 2.

Tabela 2 - Tamanho da propriedade, número de vacas lactantes, produção e produtividade em 274 Unidades de Produção de Leite (UPL) de municípios da região sul do Rio Grande do Sul

\begin{tabular}{|c|c|c|c|c|c|c|}
\hline \multirow[b]{2}{*}{ Município (n) } & \multirow{2}{*}{$\begin{array}{l}\text { Área média } \\
\text { da UPL } \\
\text { (ha) }\end{array}$} & \multicolumn{2}{|c|}{ Vacas lactantes } & \multicolumn{3}{|c|}{ Produção de leite (\%) } \\
\hline & & média & $\begin{array}{l}\text { Produtividade } \\
\text { (L/vaca/dia) }\end{array}$ & $<50 \mathrm{~L}$ & $50-200 \mathrm{~L}$ & $>200 \mathrm{~L}$ \\
\hline Pelotas (65) & $36,72 \mathrm{a}$ & $10 \mathrm{~b}$ & $6,98 \mathrm{a}$ & $24,57 \mathrm{~b}$ & $66,66 \mathrm{a}$ & $8,77 \mathrm{c}$ \\
\hline Canguçu (69) & $23,84 b$ & $6,5 \mathrm{c}$ & $4,75 b$ & 55,07 a & $40,58 \mathrm{c}$ & $4,35 d$ \\
\hline Cerrito (62) & $18,36 \mathrm{c}$ & $7,1 \mathrm{~b}$ & $7,14 \mathrm{a}$ & $35,48 \mathrm{~b}$ & $54,84 \mathrm{~b}$ & $9,68 \mathrm{c}$ \\
\hline Rio Grande (16) & $34,84 \mathrm{a}$ & $16,7 \mathrm{a}$ & $7,44 a$ & $12,5 d$ & $37,5 \mathrm{c}$ & $50 \mathrm{a}$ \\
\hline Morro Redondo (37) & $20,93 \mathrm{~b}$ & $6,6 \mathrm{c}$ & $6,98 \mathrm{a}$ & $29,73 b$ & $62,16 \mathrm{a}$ & $8,11 \mathrm{c}$ \\
\hline São Lourenço do Sul (25) & $28,64 a b$ & $10,6 \mathrm{~b}$ & $7,5 \mathrm{a}$ & $20 c$ & $52 b$ & $28 \mathrm{~b}$ \\
\hline
\end{tabular}

Picoli et al. (2015) relataram que o tamanho médio das propriedades onde era praticada a atividade leiteira na mesorregião sudeste do Rio Grande do Sul era de 26,06 ha, porém $50,6 \%$ das propriedades avaliadas naquele estudo praticavam a atividade em áreas menores que 20 ha. No presente estudo, os municípios de Pelotas e Rio Grande se destacaram dos demais pela área média das propriedades rurais. O relevo acidentado de determinados municípios como Morro Redondo, Cerrito e Canguçu pode ser um fator importante para que as propriedades tenham pequena área. Historicamente, nestes municípios, as propriedades 
são de pequeno porte e com baixa produção leiteira. Isso dificulta a aquisição de novas áreas afim de aumentar a produção e a produtividade.

Na região norte do Rio Grande do Sul, a atividade leiteira vem sendo desenvolvida em área média de 18,8 ha com média de 17 vacas em lactação. Esses índices são superiores aos encontrados na região sul do estado, porém trata-se de uma região com tradição e certa especialização na produção de leite, mas ainda assim, longe de atingir seu potencial (MILANI et al., 2012). Nos estudos de Picoli et al. (2015), as propriedades leiteiras trabalhavam com média de 8,4 vacas em lactação, sendo que $73,6 \%$ das propriedades trabalhavam com menos de 10 vacas em lactação, e no presente estudo a média entre todos os município estudados foi de 9,5 vacas em lactação sendo que, novamente os municípios de Canguçu, Cerrito e Morro Redondo se destacaram por terem mais de $80 \%$ de seus produtores com menos de 10 vacas em lactação, porém Canguçu teve o pior desempenho no que diz respeito à produtividade, com média de 4,75 L/vaca/dia. Rio Grande foi o município com melhor produtividade $(7,44 \mathrm{~L} / \mathrm{vaca} / \mathrm{dia})$.

Com relação ao volume da produção de leite, Picoli et al. (2015) encontraram valores semelhantes ao presente estudo indicando que 13,21\% das UPL produziam até 30 litros por dia, 21,13\% produziam entre 30 e 50 litros/dia, 32,83\% produziam entre 50 e 100 litros, 20\% entre 100 e 200 litros, 10,94\% entre 200 e 500 litros e apenas 1,89\% das UPL produziam acima de 500 litros de leite por dia. A produtividade média dos animais encontrada por esses autores ficava em torno de 6,8 L/vaca/dia. O baixo número de vacas em lactação está associado à baixa produção, porém a produtividade desses animais é um fator a ser considerado, visto que o manejo pode interferir na produção individual dos animais.

No presente estudo, o município de Rio Grande apresentou melhor desempenho quanto à produção leiteira, já que 50\% das UPL visitadas produziam mais de 200 litros de leite por dia. Isso se deve provavelmente ao fato de que o número médio de vacas em lactação é superior aos demais municípios (16,7 vacas) e a fatores relacionados ao manejo, como ordenha mecanizada e desinfecção dos tetos pré-ordenha. No entanto, é importante salientar o baixo número de amostras coletadas neste município $(n=16)$, e se torna representativo de apenas 
uma das rotas dos caminhões coletores de leite que abrange desde o povoado do Capão Seco até o Povo Novo.

O município de Rio Grande apesar de ter uma porcentagem elevada de donos das UPL com ensino fundamental incompleto, possui propriedades mais estruturadas que utilizam melhores técnicas de produção. Isto se deve possivelmente a uma maior assistência no município e ao fato de que os produtores entraram na atividade mais recentemente que nos demais municípios.

Quanto à caracterização do manejo de ordenha, a Tabela 3 apresenta os dados e os números indicam que $87,5 \%$ das UPL utilizam ordenha mecânica em Rio Grande, fato que minimiza a contaminação externa, desde que os equipamentos sejam bem manejados. Os riscos de contaminação ambiental nesse município são diminuídos, pois $68,7 \%$ das UPL tem suas instalações de alvenaria e piso de cimento, o que facilita a higienização do ambiente e tem a maior taxa de adesão a prática de desinfecção dos tetos antes da ordenha $(43,7 \%)$. No entanto, a Tabela 4 revela que este município apresenta as maiores contagens bacterianas no leite contido nos resfriadores. Esse alarmante dado pode indicar falta de higiene nos procedimentos extra ordenha, como armazenamento do leite e desinfecção de equipamentos (tarros, resfriadores, mangueiras) de modo ineficazes.

Tabela 3 - Caracterização do manejo da ordenha em Unidades de Produção de Leite (UPL) de municípios da região sul do Rio Grande do Sul ( $n=274)$.

\begin{tabular}{|c|c|c|c|c|c|c|c|}
\hline \multirow[b]{2}{*}{ Município (n) } & \multirow{2}{*}{$\begin{array}{l}\text { Ordenha } \\
\text { manual } \\
(\%)\end{array}$} & \multirow{2}{*}{$\begin{array}{l}\text { Desinfecção } \\
\text { pré-ordenha } \\
\text { (\%) }\end{array}$} & \multicolumn{3}{|c|}{ Secagem do teto (\%) } & Instalações & \multirow{2}{*}{$\begin{array}{l}\text { Piso } \\
\text { terra } \\
(\%)\end{array}$} \\
\hline & & & $\begin{array}{l}\text { Papel } \\
\text { toalha }\end{array}$ & Pano & Nenhum & $\begin{array}{l}\text { de madeira } \\
(\%)\end{array}$ & \\
\hline Pelotas (65) & $26,2 \mathrm{~b}$ & $12,2 \mathrm{~b}$ & $32,7 a$ & $46,2 \mathrm{~b}$ & $21,1 \mathrm{~b}$ & $56,1 \mathrm{a}$ & $14,0 \mathrm{c}$ \\
\hline Canguçu (69) & $46,4 \mathrm{a}$ & $7,2 \mathrm{c}$ & $10,4 \mathrm{c}$ & $56,7 \mathrm{a}$ & $32,9 \mathrm{~b}$ & $56,5 \mathrm{a}$ & $33,3 \mathrm{~b}$ \\
\hline Cerrito (62) & $50,0 \mathrm{a}$ & $6,7 \mathrm{c}$ & $31,7 \mathrm{a}$ & $65,0 \mathrm{a}$ & $3,3 d$ & $62,9 a$ & $58,1 \mathrm{a}$ \\
\hline Rio Grande (16) & $12,5 \mathrm{c}$ & $43,7 \mathrm{a}$ & $43,8 \mathrm{a}$ & $43,8 \mathrm{~b}$ & $12,4 \mathrm{c}$ & $31,3 c$ & $18,8 \mathrm{c}$ \\
\hline Morro Redondo (37) & 56,8 a & $13,5 b$ & $35,1 \mathrm{a}$ & $64,9 \mathrm{a}$ & $0,0 \mathrm{e}$ & $45,9 \mathrm{~b}$ & 56,8 a \\
\hline São Lourenço do Sul (25) & $12,0 \mathrm{c}$ & $16,0 \mathrm{~b}$ & $20,0 \mathrm{~b}$ & $28,0 \mathrm{c}$ & $52,0 \mathrm{a}$ & $48,0 \mathrm{~b}$ & $24,0 \mathrm{~b}, \mathrm{c}$ \\
\hline
\end{tabular}

Letras distintas na mesma coluna indicam diferença estatística pelo teste Qui-quadrado com nível de significância de $95 \%$. 
No presente estudo, apenas $14,2 \%$ das UPL estudadas realizavam a desinfeç̧ão préordenha. É uma porcentagem baixa, visto a importância da realização da técnica. Porém, mesmo no norte do Estado, em uma região tradicional na produção de leite, apenas 16,3\% dos entrevistados afirmam realizar o procedimento (MILANI et al., 2012).

Quanto à secagem dos tetos, é interessante observar a CCS no município de São Lourenço do Sul (Tabela 4), que tem a menor porcentagem de produtores que secam os tetos antes da ordenha, porém apresentou uma das menores CCS. No município de Canguçu, 56,7\% das UPL utilizavam o pano para secagem dos tetos e sua CCS é bem mais elevada. O pano veicula micro-organismos de um quarto infectado para outro sadio e este dado é comprovado por Picoli et al. (2014), que demonstraram maior chance de ocorrência de Streptococcus agalactiae como causador de mastite em UPL que utilizam um pano único nos animais para secagem dos tetos e ainda afirmam que é preferível não lavar ou secar os tetos a usar o pano.

Um fator que chamou a atenção no presente estudo é a precariedade das instalações onde se maneja o gado leiteiro. No município de Cerrito, 62,9\% dos produtores ainda realizam o processo de obtenção do leite em estábulos de madeira e 58,1\% tem o piso de terra. Estas características podem prejudicar a correta higienização do ambiente, sendo fatores epidemiologicamente importantes na predisposição à ocorrência de mastites no rebanho ou ao aumento da contagem bacteriana total do leite do tanque. A Tabela 4 corrobora com tais afirmações, já que o citado município apresenta elevadas CCS e CBT, acima dos valores recomendados pela legislação vigente.

Quanto às análises de qualidade do leite, as médias dos teores de gordura, proteína bruta, lactose, sólidos totais, CCS e CBT estão apresentadas na Tabela 4. Nem todas as propriedades estavam em conformidade com as exigências da legislação. No Brasil, a partir de 2012, foi estabelecida a Instrução Normativa no 62 (IN62) e, por esta norma, os limites atuais para CCS são de $400 \mathrm{mil}$ células/mL de leite para as regiões Sul e Sudeste (BRASIL, 2011). Quanto à CBT, atualmente a IN62 estabelece o valor de $100 \mathrm{mil}$ UFC/mL de leite (BRASIL, 2011). 
Tabela 4 - Qualidade e composição do leite de 274 UPL em municípios da região sul do Rio Grande do Sul.

\begin{tabular}{|c|c|c|c|c|c|c|}
\hline Município (n) & $\begin{array}{l}\text { Gordura } \\
\text { (\%) }\end{array}$ & $\begin{array}{l}\text { Proteína } \\
(\%)\end{array}$ & $\begin{array}{l}\text { Lactose } \\
\text { (\%) }\end{array}$ & $\begin{array}{l}\text { Sólidos Totais } \\
\text { (\%) }\end{array}$ & $\begin{array}{l}\text { CCS } \\
\left(\times 10^{5}\right)\end{array}$ & $\begin{array}{l}\text { CBT } \\
\left(\times 10^{6}\right)\end{array}$ \\
\hline Pelotas (65) & $3,77 \mathrm{~b}$ & $3,15 \mathrm{a}$ & $4,4 \mathrm{a}$ & $12,33 \mathrm{~b}$ & $6,39 a$ & $1,69 \mathrm{c}$ \\
\hline Canguçu (69) & $4,23 a$ & 3,49 a & $4,41 \mathrm{a}$ & $13,12 \mathrm{a}$ & $6,7 \mathrm{a}$ & $4,48 \mathrm{~b}$ \\
\hline Cerrito (62) & $4,55 \mathrm{a}$ & $3,52 \mathrm{a}$ & $4,31 \mathrm{a}$ & $13,28 \mathrm{a}$ & $5,11 b$ & $5,24 b$ \\
\hline Rio Grande (16) & $3,9 \mathrm{~b}$ & 3,29 a & $4,22 \mathrm{a}$ & $12,21 b$ & $4,86 b$ & $8,32 \mathrm{a}$ \\
\hline Morro Redondo (37) & $4,54 \mathrm{a}$ & 3,59 a & $4,31 \mathrm{a}$ & $13,28 \mathrm{a}$ & $3,31 \mathrm{c}$ & $2,62 \mathrm{c}$ \\
\hline São Lourenço do Sul (25) & $3,68 b$ & $3,16 \mathrm{a}$ & $4,33 a$ & $12,19 \mathrm{~b}$ & $3,65 \mathrm{c}$ & $3,47 c$ \\
\hline
\end{tabular}

Letras distintas na mesma coluna indicam diferença estatística pelo teste Tukey com nível de significância de 95\%.

No que diz respeito à CCS, 162 UPL $(59,1 \%)$ estavam de acordo com as exigências da legislação enquanto que apenas 102 (37,2\%) estavam de acordo com os padrões exigidos com relação à CBT. Esses dados demonstram que um dos grandes problemas e entraves na produção leiteira no sul do Rio Grande do Sul está no manejo da ordenha e no armazenamento desse leite, já que altas CBT estão relacionadas à precariedade na higiene do processo de obtenção do leite.

Observa-se que não houve diferenças entre os teores de proteínas e lactose entre os municípios, porém os teores de gordura diferiram e, os municípios que apresentam maiores teores de gordura, apresentam também os maiores teores de sólidos totais. Dessa forma, é possível afirmar que a gordura é o componente que mais varia na composição do leite produzido nos locais estudados, possivelmente devido às diferenças nas dietas dos animais. Santos e Fonseca (2007) afirmam que o teor de gordura do leite tem correlação alta e positiva com a concentração molar de ácido acético e butírico no rúmen, que são provenientes da dieta, após fermentação.

Houve correlação negativa entre a produção e a $\operatorname{CCS}(r=-0,23, n=274, p<0,05)$, ou seja, quanto maior a CCS do rebanho, menor a produção observada, o que corrobora com Philpot (1998) que descreve que, com a CCS elevada a produção diminui. A correlação entre CBT e CCS foi de 0,21 ( $n=274, p<0,05)$, indicando que as variáveis aumentam simultaneamente. Isso pode significar que uma grande parte das bactérias totais presentes em leite de 
resfriadores são provenientes de quartos com mastite, já que CCS é indicativo de saúde da glândula mamária.

Observou-se correlação positiva entre a porcentagem de lactose e produção de leite ( $r=$ $0,31, n=274, p<0,01)$. A lactose está relacionada à regulação da pressão osmótica na glândula mamária, de forma que maior produção de lactose determina maior produção de leite (PERES, 2001). Com relação aos demais componentes do leite, houve correlação negativa com a produção (gordura, $r=-0,21$; proteínas, $r=-0,23$; sólidos totais, $r=-0,26$ ). Isso se deve à diluição desses componentes em grande volume de leite. De fato, é normal que os sólidos do leite estejam em menores concentrações conforme aumenta o volume produzido, porém isso não influencia, segundo a legislação vigente, na remuneração do produtor, que recebe pelo volume produzido, pela CCS e CBT (BRASIL, 2011).

Em casos de mastite, a redução no volume produzido se dá pela lesão nas células epiteliais, diminuindo a produção de lactose. No presente estudo, houve correlação negativa entre os níveis de CCS e os teores de lactose $(r=-0,39, n=274, p<0,01)$, que concordam com estudos realizados por Gonzalez et al. (2006), em propriedades leiteiras da mesma região.

\section{CONCLUSÃO}

Após a observação e análise dos resultados, constatou-se que o leite da região sul do Rio Grande do Sul ainda é produzido de forma precária, seja por conta das instalações, higiene ou do manejo da ordenha, características que se refletem na qualidade do produto final, que em alguns casos apresentam-se fora dos padrões mínimos exigidos pela legislação. De maneira geral, a maioria dos produtores de leite da região são alfabetizados, porém com baixo grau de instrução. Os dados comprovaram que o produto obtido tem qualidade inferior em locais onde são adotadas técnicas precárias de manejo. 


\section{COMPARATIVE STUDY OF DAIRY PRODUCTION IN MUNICIPALITIES OF THE SOUTH REGION OF RIO GRANDE DO SUL}

\section{ABSTRACT}

B razilian milk production is characterized by containing individual production systems. This way, the objective was to characterize the milk production in municipalities in Southern Rio Grande do Sul and check the factors that mostly affect milk quality in the region, through an epidemiological survey and milk quality analysis in the production units. The research has shown that the average age of farmers is 49 years old and $64.15 \%$ of them did not complet primary school. Milk production is performed in properties with an average of 26.06 hectares, with 8.4 dairy cows on average, and $93.6 \%$ of the units have less than 20 cows. Most units (32.83\%) yield 50 to $100 \mathrm{~L} /$ day; $13.21 \%$ produce up to $30 \mathrm{~L}$ per day and only $1.89 \%$ yield above $500 \mathrm{~L}$ per day. The detected average productivity was $6.8 \mathrm{~L} / \mathrm{cow} /$ day. About milking handling, $39.3 \%$ are still milking manually their animals, only $14.2 \%$ performed pre-milking teat disinfection and $53.9 \%$ use a single cloth to dry the teats. There was a negative correlation between somatic cell count (SCC) and milk production $(r=-0.23)$ and between SCC and lactose content $(r=-0.39)$. There was a positive correlation between lactose content and production $(r=0.31)$. The data show that the quality of the product obtained is inferior in places where poor milking handling techniques are adopted.

Keywords: Milking. Milk quality. Small farmers.

\section{ESTUDIO COMPARATIVO DE LA PRODUCCIÓN LECHERA EN MUNICIPIOS DE LA REGIÓN SUR DEL RIO GRANDE DO SUL}

\section{RESUMEN}

a producción brasileña de leche se caracteriza por contener sistemas de producción individuales. El objetivo fue caracterizar la producción de leche en los municipios del sur de Rio Grande do Sul y verificar los factores que más afectan la calidad de la leche en la región, mediante una encuesta epidemiológica y un análisis de la calidad de la leche en las unidades de producción. La investigación ha demostrado que la edad promedio de los agricultores es de 49 años y el $64,15 \%$ de ellos no han terminado la escuela primaria. La producción de leche se realiza en propiedades con un promedio de 26,06 hectáreas, con 8,4 vacas lecheras en promedio, y $93,6 \%$ de las unidades tienen menos de 20 vacas. La mayoría de las unidades $(32,83 \%)$ producen 50 a 100 L/ día; $13,21 \%$ producen hasta 30 L por día y sólo el $1,89 \%$ produce más de $500 \mathrm{~L}$ por día. La productividad promedio detectada fue de 6,8 L/vaca/día. En cuanto a la manipulación del ordeño, el 39,3\% sigue ordeñando manualmente sus animales, solo el 14,2\% realizó la desinfección previa del ordeño y el 53,9\% utiliza un solo paño para secar las tetas. Hubo una correlación negativa entre el recuento de células somáticas (RCC) y la producción de leche $(r=-0,23)$ y entre RCC y contenido de lactosa ( $r=-$ $0,39)$. Hubo una correlación positiva entre el contenido de lactosa y la producción $(r=0,31)$. 
Los datos muestran que la calidad del producto obtenido es inferior en lugares donde se adoptan malas técnicas de manipulación de ordeñe.

Palabras clave: Ordeñe. Calidad de la leche. Pequeños agricultores.

\section{REFERÊNCIAS}

BRASIL. Instrução Normativa no 62 de 29 de dezembro de 2011. Alteração do caput da Instrução Normativa MAPA no51, de 18 de setembro de 2002. Diário Oficial da União, Brasília, 29 de dezembro de 2011.

BRITO, M. A. V. P.; BRITO, J. R. F.; PORTUGAL, J. A. B. Identificação de contaminantes bacterianos no leite cru de tanques de refrigeração. Revista do Instituto de Laticínios Cândido Tostes, v. 57, n. 327, p. 83-88, 2002.

COSTA, E. O.; WATANABE, E. T. Tratamento de mastite. In: ENCONTRO DE PESQUISADORES EM MASTITE. Botucatu. Anais. Botucatu: Faculdade de Medicina Veterinária e Zootecnia, p. 87-101, 1999.

GONZALEZ, H. L.; FISCHER, V.; RIBEIRO, M. E. R.; STUMPF, W.; GOMES, J. F. G.; FAGUNDES, C. M.; SILVA, M. A. Comparação da qualidade do leite em diferentes sistemas de produção da bacia leiteira de pelotas, RS. Revista Brasileira Agrociência, v. 12, n. 4, p. 475-482, 2006.

IBGE - INSTITUTO BRASILEIRO DE GEOGRAFIA E ESTATí́STICA. Censo Agropecuário 2006. Disponível em:

<http://www.ibge.gov.br/home/estatistica/economia/agropecuaria/censoagro/2006/agrope cuario.pdf>. Acesso em: 01 de março de 2016.

IBGE - INSTITUTO BRASILEIRO DE GEOGRAFIA E ESTATÍSTICA. Estatística da Produção Pecuária, 2015. Disponível em:

<http://www.ibge.gov.br/home/estatistica/indicadores/agropecuaria/producaoagropecuari a/abate-leite-couro-ovos_201501_publ_completa.pdf>. Acesso em: 01 de março de 2016.

MILANI, R.; SPANEVELLO, R. M.; LAGO, A.; ZORZI, A. M. Diversificação e perspectivas de investimentos entre produtores de leite. In: ENCONTRO DE ECONOMIA GAÚCHA, 6, 2012, Porto Alegre. ANAIS. Porto Alegre: PUCRS, 2012.

PERES, J. R. O leite como ferramenta do monitoramento nutricional. In: USO DO LEITE PARA MONITORAR A NUTRIÇÃO E O METABOLISMO DE VACAS LEITEIRAS, 2001, Passo Fundo, ANAIS. 2001.

PHILPOT, W. N. Importância da contagem de células somáticas e outros fatores. In: SIMPÓSIO INTERNACIONAL SOBRE QUALIDADE DO LEITE, 1., 1998, Curitiba. ANAIS. Curitiba: Biblioteca do Setor de Ciências Agrárias - UFPR, 1998. P. 1-6. 
PICOLI, T.; ZANI, J. L.; BANDEIRA, F. S.; ROLL, V. F. B.; RIBEIRO, M. E. R.; VARGAS, G. D.; HUBNER, S. O.; LIMA, M.; MEIRELES, M. C. A.; FISCHER, G. Manejo de ordenha como fator de risco na ocorrência de micro-organismos em leite cru. Semina: Ciências Agrárias, v. 35, n. 4, p. 2471-2480, 2014.

PICOLI, T.; ZANI, J. L.; PETER, C. M.; ROLL, V. F. B.; RIBEIRO, M. E. R.; VARGAS, G. D. V.; HÜBNER, S. O.; LIMA, M.; FISCHER, G. Milk production characteristics in Southern Brazil. Semina: Ciências Agrárias, v. 36, n. 3, Supl. 1, p. 1991-1998, 2015.

SANTOS, M. V.; FONSECA, L. F. L. Estratégias de para o Controle de mastite e Melhoria da Qualidade do Leite. São Paulo: Manole, 2007. 314p.

SAS - Software \& Soluções de Analytics. SAS/Stat user's guide. Version 9.1. Cary: SAS Institute, 2004.

SCALCO, A. R.; SOUZA, R. C. Qualidade na cadeia de produção de leite: diagnóstico e proposição de melhorias. Organizações Rurais \& Agroindustriais, Lavras, v. 8, n. 3, p. 368377, 2006.

SCHÄELLIBAUM, M. Efeitos de altas contagens de células somáticas sobre a produção e qualidade de queijos. In: SIMPÓSIO INTERNACIONAL SOBRE QUALIDADE DO LEITE, 2, 2000, Curitiba. ANAIS. Curitiba: CIETEP/FIEP, p. 21-26, 2000.

SCHUCH, L. F. D.; ZANI, J. L.; MARQUES, L. T.; DORNELES, T.; PAZ, F. D.; ALBARELLO, C. E.; PICOLI, T.; RIBEIRO, M. E. R. Tecnologias sustentáveis e estratégias de comunicação rural para qualificação da produção leiteira na agricultura familiar. In: CONGRESSO IBEROAMERICANO DE EXTENSIÓN, 10, 2009, Montevideo. RESÚMENES. Montevideo: Universidade de la República, 2009.

SCHULTZ, L. H. Somatic cells in milk physiological aspects and relationship to amount and composition of milk. Journal of Food Protection, v. 40, p. 125-131, 1977.

TOZZETTI, D. S. Prevenção, controle e tratamento das mastites bovinas - revisão de literatura. Revista Científica Eletrônica de Medicina Veterinária, n. 10, 2008.

USDA - United States Departament of Agriculture. USDA Foreign Agricultural Service, 2014. Disponível em: <http://apps.fas.usda.gov/psdonline/>. Acesso em: 01 de março de 2015.

Autor para correspondência: Tony Picoli. Laboratório de Virologia e Imunologia, Faculdade de Veterinária, Avenida Eliseu Maciel, s/no, Campus Universitário, prédio 1, Capão do Leão (RS), CEP 96010-900. picolivet@gmail.com 